\title{
Ecological Strategies on the Demonstration of the Western Route Water Transfer
}

\author{
WANG Tongtong ${ }^{1}$, CHEN $\mathrm{Hao}^{2}$ \\ ${ }^{1}$ Bureau of South-to-North Water Transfer of Planning, Designing and Management, MWR, P. R. China \\ 2.Sichuan Water Resources and Hydroelectric Investigation \& Design Institute
}

\begin{abstract}
To comply with the national strategic layout adjustment in recent years, and to promote ecological civilization construction in China western region, it is necessary to study the opportunities and challenges in the Western Route Water Transfer demonstration brought by in ecological and environmental changes in both water-source regions and water receiving regions. By referring to the operation management experience of the Eastern and Middle routes of the South-to-North Water Transfer Project, this paper analyzed the ecological and environmental changes of the Western Route Project's water transfer rivers, and the relationship between water and sediment of the Yellow River in water-receiving regions, found out the integrating point between the Western Route Project and the new development ideas, and finally concluded that the ecology must be given to priority in the demonstration of the Western Route Project. The early stage work of the Western Route Project needed to follow the general principles as for any major water conservancy project, which includes to demonstrate the project necessity given fully employing the water-saving potential, and to give highest priority to ecological security. Several relationships need be coordinated between: water source regions and water-receiving regions in water-saving, water ecological restoration and water resources development, water pollution control and water resources management, government leading and society participation, etc. These instruments above will guarantee both the water-source and water-receiving regions could benefit from the Western Route Project, help to solve the contradiction between ecological protection and water resources allocation, and facilitate achieving the target of sustainable development.
\end{abstract}

\section{Foreword}

The South-to-North Water Transfer Project (SNWTP), consisting of eastern, middle and western routes, is a strategical water transfer project aiming at optimal allocation of water resources in China. The Western Route Project (WRP) is designed to diverting water from the upper Yangtze River into the upper Yellow River, and the water transfer scale of the first phase is annually 8 billion $\mathrm{m}^{3}$. While over the past decade, some changes have happened to SNWT. The first phases of the eastern and middle routes are put into operation separately in Nov 2013, and Dec 2014. In the continued preliminary demonstration of the western route, the primary consideration has been focused on minimizing the impact of water transfer on ecology. Meanwhile, with speeding up promoting the ecological civilization construction by central government recently, new ideas on green development are gradually made public, such as "Humankind develops in harmony with nature", "Lucid waters and lush mountains are invaluable assets". Based on the analysis of new situation and new changes, this paper puts forward relevant thoughts on how to fully reflect the principle of ecological priority in the WRPSNWT's preparation work, and how to improve the support of the WRP-SNWT to the ecological protection of Northwest China and the Yellow River basin.

\section{New situations and requirements on the demonstration of the WRP}

The 13th Five-Year Plan for Reform and Development of Water Resources proposed that the preliminary demonstration of the WRT should be further deepened, according to the new situations, ideas, and requirements of economic and social development, and changes of water and sand in the Yellow River basin. It can be said that the decision-making background of the western route has changed.

\subsection{The adjustment of national development strategy provides opportunities and policy supports for the implementation of the WRP}

At present, China has placed ecological civilization construction at an unprecedented height, and the idea of modern water control has been highly valued. The government stepped to implement the Yangtze Economic Belt development strategy, and proposed that "We must proceed from the long-term interests of the Chinese nation 
to put restoring the ecological environment of the Yangtze River at a dominant position, making all-out efforts to protect it, and forbidding large-scale development of the river." The water transfer area of the WRP is located in the ecological protective screen of the upper Yangtze River, so special attention should be paid to the relationship between river basin development and ecological environment protection, especially the water source protection.

And in recent years, China has vigorously pursued the Belt and Road Initiative, in which the Silk Road Economic Belt covers the upper and middle Yellow River, which is also the WRT water-receiving area. The implementation of the Belt and Road Initiative has raised higher requirements for water security in upper- middle Yellow River and provided opportunities for the WRP. The WRP can alleviate the serious water shortage in water-receiving area, improve the ecological environment, maintain the healthy life of the Yellow River, and provide effective water resource guarantee for the Belt and Road Initiative.

\subsection{Changes in water source area have an impact on the ecological environment of the water- transfer rivers}

The water-transfer rivers of the WRP involves the Tongtian River, the main stream of Yalong River and its branches such as Daqu River, Niqu River, and Dadu River branches such as Sequ River, Duke River, Make River and Ake River. The water transfer scale of the first stage is 8 billion $\mathrm{m}^{3}$, and the planned water transfer line is shown in figure 1 .

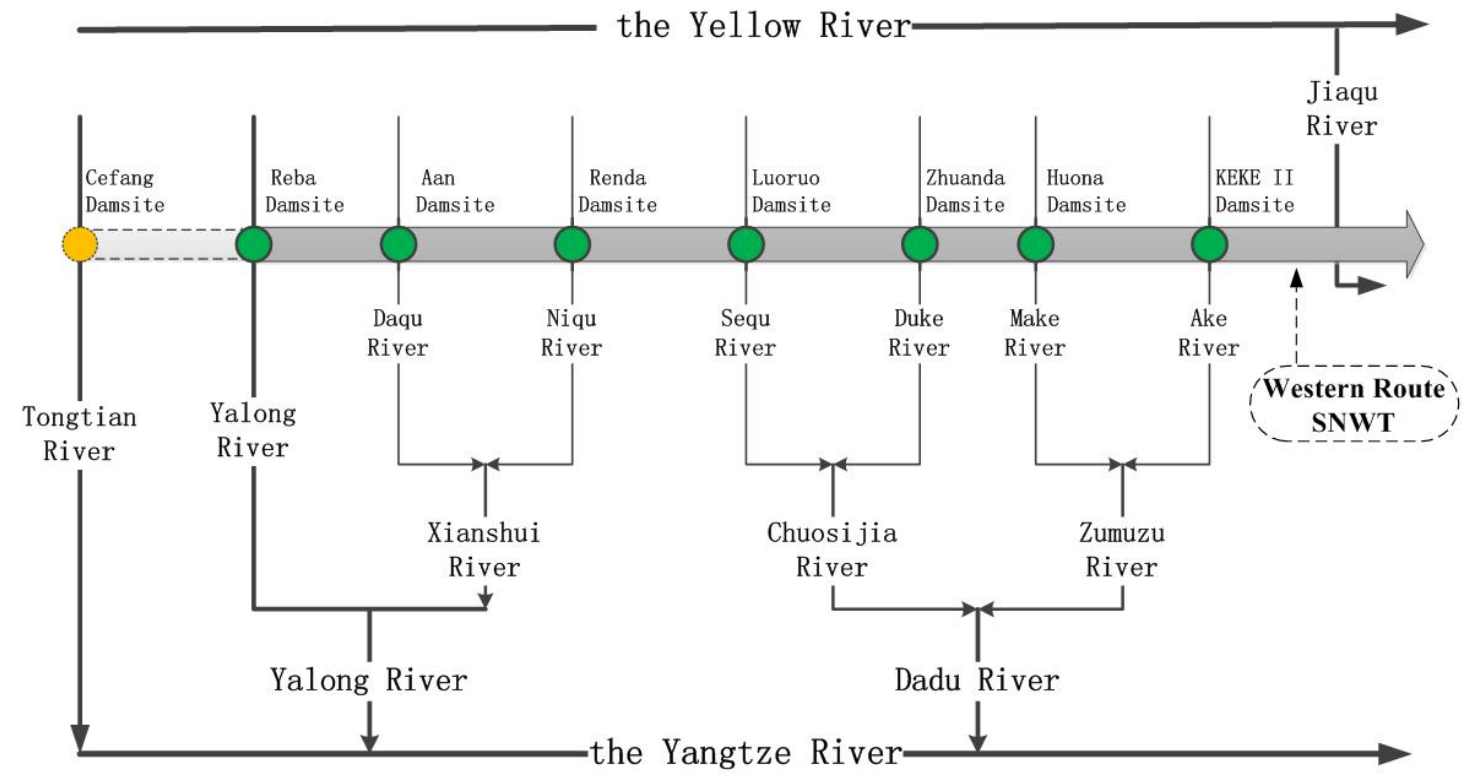

Figure 1 Generalization of the WRP Water Transfer Rivers

In recent years, some changes in water transfer area have made an impact on the ecological environment of the water-transfer rivers. The first is to develop hydropower stations. In Sichuan Province, large-scale and highintensity development of hydropower resources has been carried out. Both Lianghekou and Shuangjiangkou hydropower stations have successively started up, which would have a significant impact on the hydrological situation of the water-transfer rivers when completed. In addition, some small-scale hydropower stations have been newly-built across the water-transfer rivers, which further compress the length of the natural continuous rivers. The second is to demarcate protection areas. Part of the Make River has been demarcated as the National Aquatic Germplasm Resources Conservation Zone. Some reaches of Make River and Ake River and their branches in Sichuan Province, have been demarcated as Special Fish Hucho bleekeri Reserves in Upper Dadu River. Development is restricted or prohibited in these areas. The third is to build a number of large projects. The government has built up large infrastructure facilities such as Qinghai-Tibet Railway, Zipingpu Hydropower Station and Erlang Mountain Tunnel near the planned area of the western route, whose influence on the ecological environment has also provided a valuable reference for the WRP.

\subsection{Both incoming water and sediment from the Yellow River show a downward trend, but the relationship between water and sediment is still uncoordinated}

In recent years, with little changes in precipitation, the amount of incoming water and sediment in the Yellow River basin has been greatly reduced, and the reduction of sediment is much larger than that of water amount. It is estimated that the annual water inflow of the Yellow River in 2001-2012 was about 12\% lower than that in 1956-2000, and the sediment decreased about $76 \%$. However, the relationship between the water and sand is still uncoordinated. There is a large water gap in sediment transport during flood season. Under the joint application of Longyangxia Reservoir and Liujiaxia Reservoir, there is more sediment and less water in Ning-Meng Reach in the flood season. The non-flood season has evolved into 
the main water transfer period. The situation of overhanging river in the lower reaches of Inner Mongolia River continues to extend to the upper-middle Yellow River, threatening the safety of flood control and ice prevention. Due to Xiaolangdi Reservoir's joint action to block sediment and divert water and sediment, the minimum conveyance capacity of the main lower reaches has been partially restored. However, it is limited for Xiaolangdi Reservoir to adjust water and sediment with a capacity of only 1 billion $\mathrm{m}^{3}$. Maybe and the lower reaches of the Yellow River will face the risk of rapid siltation.

\subsection{The operation of the Eastern and Middle Route provides a reference for the WRP}

The SNWTP is an important component of the national water network, whose three routes are interrelated and refer to each other. By the end of 2017, the Eastern Route Project had cumulatively transferred over 2.2 billion $\mathrm{m}^{3}$ to Shandong Province, and the Middle Project had cumulatively transferred over 11 billion $\mathrm{m}^{3}$ to the waterreceiving areas. In 2014, the Eastern Route Project transferred 80 million $\mathrm{m}^{3}$ to Nansihu Lake for ecological water supplement, which timely mitigated the drought in the lake. And in 2018, the Middle Route Project transferred 868 million $\mathrm{m}^{3}$ to Tianjin, Hebei and Henan Province to raise the groundwater level and improve the water ecological environment. However, the Eastern Route and Middle Route have achieved significant ecological benefits while also producing certain negative effects. For example, water quality in some sections of the Eastern Route is unstable, and the Middle Route affects the ecological water in lower reaches of the Hanjiang River. Therefore, it is necessary to summarize the experience and problems in their initial operating stage, which will provide references in the demonstration of the WRP.

\section{Requests conservancy principles \\ of major water project demonstration}

To demonstrate major projects, the government need adhere to principles of "actually demand, ecological security and sustainability". Thus, the WRP should strictly follow the above principles in its preliminary demonstration, which will take water conservation works as the premise, focus on ensuring ecological security, and achieve the goal of sustainable development.

\subsection{It is a prerequisite to give high priority to water conservation}

The utilization rate of surface water in the Yellow River basin is far higher than average. Agriculture, as the main water-use type in the Yellow River basin, is the key object of water conservation, but its water-saving potentiality is restricted by the autumn irrigation in the upper-middle Yellow River, complex irrigation and drainage network in super-large irrigation areas, and hyper-concentrated flow in the Yellow River. Recently, the government has established the strictest water resources management system, declaring the "Three Red Lines". Thus, 6 provinces in water-receiving area of the WRP, have been constrained to adopt engineering, technology, economy, management and other measures to improve water conservation level. Since 2003, the MWR has carried out pilots on water exchange, and cultivated water market in Ning-Meng Reach. By way of water-saving reform in irrigation areas, Ningxia and Inner Mongolia autonomous regions have replaced the saved agricultural water right with the industrial water right, with a total of 228 million $\mathrm{m}^{3}$ of water converted, and 257 million $\mathrm{m}^{3}$ of water saved by water-saving projects. At the same time, the water right replacement in water-receiving areas has been extended from within an administrative region to across administrative regions. So, the decision makers should adhere to place the priority on water conservation in the Yellow River basin, constantly raise the scientificalness and precision of water conservation works, and then make further demonstration on whether the WRP is actually demanded.

\subsection{It is a key point to maintain water ecological security}

The ratio of water transfer in each dam site of the WRP is between $59.4 \%$ and $69.2 \%$, and the ratio of discharge is between $29.3 \%$ and $38.8 \%$, which may have certain influence on the growth of vegetation and aquatic organisms along the shore, and the rivers' self-purification capacity in water-intensive areas. Meanwhile, the WRP will increase the runoff in the upper-middle Yellow River, lift the groundwater level, and provide ecological water for the restoration and reconstruction of the degraded ecosystem in the northwest region, as well as discharging sediment in the Yellow River. Therefore, the decision makes should fully consider the ecological relationship between the water-transfer rivers, and the lakes and wetlands in the basin, as well as the ecological connection between the left and right banks, and the upstream and downstream, so as to meet the basic requirements of the ecological base flows and the biological habitats in watertransfer rivers. Meanwhile, it is also necessary to consider the measures to restore and protect the water ecosystem in water-receiving areas, and improve the environmental capacity and carrying capacity, so as to demonstrate the measures to minimize the impact of water transfer on the ecology in order to maintain the ecological security.

\subsection{It is an objective to realize the sustainable development}

The WRP will not only add more water supply, but also can realize the unified dispatch and management of water resources, through storing and replenishing water in multiple reservoirs, so was to alleviate the water supply and demand contradiction in the Yellow River basin and adjacent areas. Firstly, the water resources provided by the 
WRP can guarantee the water demand for key cities, industrial parks and agricultural irrigation, support the economic and social sustainable development in waterreceiving areas, and increase the electric quantity and firm power of the cascade reservoirs in the mainstream of Yellow River. Secondly, by supplying water to the Yellow River, the WRP will join the dispatch and operation with the reservoir group, regulate water and sediment in the whole river, and construct coordinating flow and sediment process in the mainstream, to gradually restore and maintain the flood discharge capacity of Ning-Meng Reach, Longmen-Tongguan Reach, and main channel downstream, etc. Thirdly, the WRP will also restore and improve the ecological environment in areas such as the Heishanxia Reach of the Yellow River, Shiyang River basin, Tala Shoal and Muge Shoal ecology restoration areas, which will have a profound impact on the ecological environment of the northwest region and the Yellow River basin. Therefore, "sustainable" should be regarded as the goal and direction of the preliminary demonstration of the WRP.

\section{The WRP's measures to implement the ecological priority principle}

In accordance with China's New Development Principles of innovative, coordinated, green, open, and shared development, as well as the policies of water conservancy in the new era, relevant measures in the WRP demonstration should be taken to implement the ecological priority principle to realize green development.

\subsection{Water-saving innovation is carried out simultaneously in water transfer area and water- receiving area}

The SNWTP principle of "first saving water then transferring water" has become a consensus. Innovatively, the water conservation is not only carried out in water transfer area, but also in water-receiving area, and the latter should place water conservation in a more prominent position.

4.1.1 Paying attention to water conservation in downstream of the water-transfer rivers can improve the water security capacity of the Yangtze River basin

Once the WRP gone into operation, the amount of water in the downstream of the water-transfer rivers might be reduced, and the water level might be dropped, which would affect amounts of water transferred by other watertransfer projects and water lifting projects downstream. Water conservation must be strengthened to ensure water demand in water transfer area. The WRP water transfer area is located in Ganzi, Aba prefectures of Sichuan Province, and Yushu, Guoluo prefectures of Qinghai Province. The regional water resources are relatively abundant, but the utilization rate, the irrigation efficiency and people's living standard are all very low. The goal of water conservation is to achieve harmonious coexistence between human and water by ensuring water supply, so it is necessary to take certain measures. For example, setting up a number of medium and small water conservancy projects for poverty alleviation, to improve regional industrial development level and realize poverty alleviation by water conservation; strengthening water quota management of key profession, and strictly controlling the discharge of industrial pollutants, to promote water conservation by pollution control; implementing high-efficiency water-saving irrigation projects in plateau regions, rainwater harvesting projects in hilly areas, and the corollary reconstruction and water-saving reform of irrigation districts, to realize agricultural water conservation; implementing soil erosion control projects, shelter forest program, and conversion cropland to forest and grassland projects, to conserve water resources in mountainous areas, improve ecological environment, and realize ecological water conservation.

\subsubsection{Deepening water-saving work in the upper- middle Yellow River can guarantee water supply security and ecological security of the basin}

China has taken many measures to water conservation in the WRP water-receiving area and achieved progressive achievement. It still needs to strengthen intensive use of water resources and ensure the basic water demand for ecological environment, on the premise of ecological security, and constrained by the carrying capacity of regional water resources. The WRP water-receiving area owns several national development zones, in which water conservation should be throughout the whole process of development, the total volume of water use should be limited, and the water use quota management should be strictly implemented. Besides, it is necessary to optimize irrigation methods in large-middle-scale irrigated areas in the upper-middle Yellow River, rationally adjust the planting structure of crops, and deeply excavate potential of agricultural conservation; strictly control the development of high-consumption water industries,carry out renovation of water-saving technologies and equipment, and develop a circular economy, etc.

\subsection{Comprehensively coordinate the relationship between water ecological rehabilitation and water resources development and utilization}

The WRP water transfer rivers are located in water source area in the upper Yangtze River, which has been listed in national key ecological function areas and national ecocivilization construction demonstration area. In this area, there are many ecological function regions, such as nature reserves, aquatic germplasm resources conservation zones, important wetlands and ecological sensitive areas, in which development is restricted or prohibited. So, it is unfit and impossible to carry out large-scale and highintensity water resources development. However, restricting development is not to restrict all water 
resources development activities, but to develop water resources in an orderly way, on the premise of no disturb to ecology and paying attention to natural ecological recovery, and on the base of resource carrying capacity and environmental capacity. Environmental standards for industrial access should be set according to the principles of ecological function restoration and conservation, or ecological mandatory protection, to allow the development of industries where local water resources and water environment can support, such as cultivating ecological products and providing ecological services. Meanwhile, more attention will be paid to intensive development, and guide the population of water transfer areas to gather in urban agglomerations with relatively concentrated economic distribution around them.

Based on water environmental carrying capacity, the water-receiving area should adhere to the principle of development by water, strictly control industrialization, urbanization and other activities, and adopt ecological restoration measures to ensure ecologic flow of major sections, and restore important wetlands and fish habitats, thus allow the over-developed Yellow River into rehabilitation in order to alleviate the ecological pressure of development activities on the Yellow River basin.

\subsection{Take the comprehensive management of water environment in water-receiving areas as important part of fulfilling new ideas of green development}

The most serious pollution areas in the upper-middle Yellow River are concentrated in the Ning-Meng Reach, Sanhuhekou-Lamawan Reach, and Tongguan-Sanmenxia Reach, all of which belong to the scope of the WRP waterreceiving area. In order to achieve the goal of green development, the water-receiving area should according to the "water pollution prevention plan" and the principle of systemic treatment, insist to undertake integrated water environment management. That is, the water-receiving area should focus on pollution reduction to reduce the total amount of pollutants, and decouple economic growth from resource and environmental load; in addition, should focus on expanding the ecological capacity, protect and restore the ecological system, enhance the service function of ecological system, especially the water ecosystem, and make it have greater capacity for acceptance and purification.

A number of energy bases in China are concentrated in water-receiving area. Industrial pollution discharge had been the main source of water pollution. However, traditional energy was gradually replaced by clean energy, after the economy had entered a period of new normal. The idea of the western route planning and demonstration should change from single water quality management to comprehensive water environment management in the basin, and bring the SNWTP water management into the Yellow River pollution control system. Meanwhile, in order to enhance the water self-purification capacity in water-receiving area, the western route planning and demonstration should emphasize the integrated protection and restoration of mountain, forest and grassland in the water receiving areas as a whole, and expand the water environmental capacity and water ecological space. Additionally, when making WRP water price policy, it is necessary to combine the comprehensive reform of agricultural water price in the water-receiving area, reasonably regulate various kinds of water sources with economic leverage, and realize the green development of the upper-middle Yellow River.

\subsection{Keep an open mind in strengthening publicity and encouraging the community to participate in the WRP demonstration}

For a long time, social sectors have paid great attention to WRP water transfer. In addition to the research and demonstration by the water sectors around the WRP, some experts and scholars, as well as social enthusiasts have also successively put forward schemes or ideas on transferring water from the west, to provide suggestions for solving the water shortage problems in the northwest region, especially in the upper-middle Yellow River basin. Accordingly, it is necessary to adhere to the concept of openness, and absorb the benefit for reference in the WRP demonstration. However, it is important to distinguish among issues of political principles, ideological understanding and academic views, firmly oppose and reject all kinds of distorted facts and subjective opinions, and actively publicize the WRP with a scientific and rigorous attitude.

Meanwhile, it is necessary to combine traditional propaganda means and internet communication to publicize the latest development of WRP demonstration, disseminate the scientific ideas of WRP in water transfer and conservation, enhance public participation and awareness, and expand WRP social influence.

In particular, publicity should be strengthened to the people in the water transfer area, so that the local people can understand that water transfer will not bring much negative impact to the local traditional way of life and the ecological environment, but will bring about rare development opportunities, which will drive infrastructure construction, increase employment opportunities, promote economic and social development and improve living standards. By publicity, the public can enhance their understanding of WRP, and the government can guide them to support and actively participate in relevant work on the western route.

\subsection{Share the benefits and development opportunities of the WRP, and construct win-win relations}

The western route cannot increase the total amount of water in both the Yangtze River and the Yellow River. It can only optimize the geographical distribution of water resources, which is regarded as a process of "spatial balance". Ganzi, Aba and Guoluo are located in the Qinghai-Tibet Plateau, and adjacent to the Sanjiangyuan reserve. Their economic development is far below the 
national average. Therefore, the decision makers should balance the coordination of water transfer area and waterreceiving area. The government should provide policy inclination and support to water-receiving area for negative impact brought by water transfer, and form composition forces with preferential and supporting policies implemented at present. In this way, the backward condition of water transfer area can be changed as far as possible, so that it can share the benefits and opportunities with water-receiving area brought by the WRP.

In the implementation of ecological compensation, the central and provincial government should increase financial transfer payments to compensate for the increased investment in environmental protection caused by water transfer. Industrial structure of water transfer area will be adjusted, and environment-friendly industries, ecotourism, green agriculture and other industries will be taken as important industrial support projects and poverty alleviation projects in areas affected by water transfer. Compensation will be made for enterprises that close down or transfer existing enterprises that do not meet environmental protection requirements. To establish the inter-regional horizontal assistance mechanism. As a beneficial area of the ecological environment, the waterreceiving area should adopt the forms of financial aid, targeted assistance and counterpart support to compensate for the loss caused by the strengthening of ecological and environmental protection in the water transfer areas. In terms of reducing the environmental impacts, it is necessary to build and rebuild the water supply projects, and build some new rolling dams to raise the water level in the lower reaches of the water transfer hub. And in water tranfer area, ecological and agricultural measures are adopted to mitigate the adverse impact of water transfer on the surrounding environment, especially to reduce the loss of flooded farmland and water amount.

\section{Conclusion}

The research on the WRP-SNWTP started in the 1950s and has been over 60 years so far. In recent years, under the influence of the national macro-strategic layout adjustment, as well as the operation of the eastern and middle routes, some changes have happened to both water transfer areas and water-receiving areas of the WRP, and the emphasis of WRP demonstration also inclines to ecological security. At present, WRP's main contradiction is between ecological protection and water resources allocation. Therefore, the decision makes should give priority to ecology, recognize the western route in the overall situation of building moderately prosperous society, find the right point of convergence between the western route and the new development ideas, study the negative impacts on the WRP ecological and environmental protection, and put forward countermeasures to support the project demonstration.

\section{References}

1. Li Guoying. Achievements of water right transfer in
Yellow River basin and its further developing objectives and measures [J]. China Water, 2010 (3) :911 .

2. Zhang Quanfa, Su ronghui, etc. The south-to-north water transfer project and its ecological security: the research priorities $[\mathrm{J}]$. Resources and Environment in the Yangtze Basin, 2007, 16 (2):217-221.

3. Ding Zixian, Shang Yuming. Analysis on the water environment influence of the west route of south-tonorth water transfer project[J]. Yellow River, 2001, 3 (10): 17-18.

4. Chang Junjie, Li Wanshou. The west route project of south-to-north water transfer project and the ecological and environmental problems in water receiving areas $[\mathrm{J}]$. Bulletin of Soil and Water Conservation, 2003, 23 (3): 6-10.

5. Peng Xiang. The west route water transfer is a strategic game concerning the overall development of China. [J]. China Soft Science S1, 2017:7-16.

6. Bureau of South-to-North Water Transfer of Planning, Designing and Management, MWR, etc. A comprehensive report on the relationship between the south-to-north water transfer project and the allocation of water resources in the Yellow River basin [R]. Beijing, P. R. China, 2012. 